\title{
Withdrawal from gamma-hydroxybutyrate, 1,4-butanediol and gamma-butyrolactone: a case report and systematic review
}

\author{
Jeremy M. Wojtowicz, MD $;^{* \dagger}$ Mark C. Yarema, MD; ${ }^{* \dagger}$ Paul M. Wax, MD $^{\S}$
}

\begin{abstract}
1,4-Butanediol (1,4-BD) is an industrial solvent that is metabolized to gamma-hydroxybutyrate (GHB), a gamma-aminobutyric acid agonist and central nervous system depressant. GHB and its analogues are popular drugs of abuse. Withdrawal from these agents is characterized by autonomic instability and altered mental status. We report a case of withdrawal from 1,4-BD lasting 6 days and complicated by new onset of seizures and rhabdomyolysis. In addition, we conducted a systematic review of the English literature pertaining to withdrawal from GHB, 1,4-BD and gamma-butyrolactone (GBL). Data collected from source articles included last use prior to symptom onset, clinical features on presentation, duration of symptoms and outcome. Twenty-seven studies with 57 episodes of withdrawal were included. Thirty-six cases (63\%) involved GHB, 3 cases (5\%) involved 1,4-BD and $18(32 \%)$ involved GBL. The most common patient symptoms were tremor $(67 \%)$, hallucinations $(63 \%)$, tachycardia (63\%) and insomnia (58\%). Seizures and rhabdomyolysis each occurred in $7 \%$ of cases, but only 1 death occurred. Emergency physicians must consider withdrawal from these agents when patients present with clinical features suggestive of a sedative-hypnotic withdrawal syndrome.
\end{abstract}

Key words: 1,4-butanediol, gamma-hydroxybutyrate, gamma-butyrolactone, substance withdrawal syndrome

\begin{abstract}
RÉSUMÉ
Le butane-1,4-diol (BD-1,4) est un solvant industriel qui se métabolise en 4-hydroxybutanoate $(\mathrm{GHB})$, un agoniste de I'acide 4-aminobutanoïque et un dépresseur du système nerveux central. Le GHB et ses analogues sont des drogues populaires faisant l'objet d'abus. Le sevrage de ces agents se manifeste par une instabilité autonome et un état mental altéré. Nous présentons un cas de sevrage de BD-1,4 ayant duré 6 jours et ayant été compliqué par une nouvelle apparition de convulsions et de rhabdomyolyse. Nous avons en outre réalisé une revue systématique de la littérature anglaise portant sur le sevrage du GHB, du BD-1,4 et du gamma-butyrolactone (GBL). Les données recueillies des articles sources incluaient des renseignements sur la dernière utilisation avant la survenue de symptômes, les manifestations cliniques à l'arrivée des patients à l'urgence, la durée des symptômes et les résultats. La revue portait sur 27 études décrivant 57 épisodes de sevrage. Trente-six cas (63\%) étaient liés au GHB, 3 cas (5\%) au BD-1,4 et 18 (32\%) au GBL. Les tremblements $(67 \%)$, les hallucinations (63\%), la tachycardie $(63 \%)$ et l'insomnie $(58 \%)$ étaient les symptômes les plus courants observés chez les patients. Les convulsions et la rhabdomyolyse se sont manifestées respectivement dans $7 \%$ des cas, mais seulement 1 décès a eu lieu. Lorsqu'un patient présente des manifestations cliniques évoquant le syndrome de sevrage de sédatifs hypnotiques, les médecins d'urgence devraient considérer la possibilité de sevrage de ces agents.
\end{abstract}

From the *Departments of Family Medicine and †Emergency Medicine, University of Calgary, Calgary, Alta., the $¥$ Department of Emergency Medicine, Calgary Health Region, Calgary, Alta., and the §Section of Toxicology, University of Texas Southwestern, Dallas, Tex.

Received: Feb. 1, 2007; revisions received: June 22, 2007; accepted: July 17, 2007

This article has been peer reviewed.

CJEM 2008;10(1):69-74 


\section{Introduction}

Originally used by bodybuilders because of perceived anabolic effects, gamma-hydroxybutyrate (GHB) and its analogues, 1,4-butanediol (1,4-BD) and gamma-butyrolactone (GBL), are frequently used to promote weight loss and improve sleep. ${ }^{1-3}$ In addition, they are used as club drugs and have gained notoriety as "date rape" drugs because of their euphoric and aphrodisiac effects. ${ }^{2}$ The Canadian Controlled Drug and Substances Act classifies GHB as a Schedule III (chemical based) drug and 1,4-BD and GBL as Schedule VI (precursors of illicit substances) drugs. ${ }^{4}$ Schedule III agents are illegal to possess or distribute, whereas Schedule VI drugs cannot legally be imported, exported or possessed for the purpose of exportation without authorization. ${ }^{4} \mathrm{GBL}$ and 1,4-BD are present in some health food products and industrial solvents, making them relatively accessible to people who seek to use them as recreational drugs. ${ }^{5}$

Withdrawal symptoms of GHB, 1,4-BD and GBL are related to central nervous system (CNS) and autonomic dysregulation, ${ }^{2,5-16}$ and are similar to withdrawal from other sedative-hypnotic drugs such as ethanol and benzodiazepines. ${ }^{17}$ While the prevalence of seizures and death during withdrawal from ethanol and benzodiazepines are known, the frequency of these complications during withdrawal from GHB analogues is unknown.

Our objectives in this review were to report a case of 1,4-BD withdrawal complicated by seizures and rhabdomyolysis, and to perform a qualitative systematic review of the literature related to withdrawal from GHB, 1,4-BD and GBL to evaluate the symptoms and clinical course that occur during withdrawal from these substances.

\section{Case report}

A 29-year-old male chemist was brought to the emergency department (ED) by his friends because of altered mental status, agitation, hallucinations and a first generalized tonic-clonic seizure. In the ED, the patient reported that he had ingested 1,4-BD every day for 5 to 6 years and that he had run out approximately 3 days earlier. He first began using 1,4-BD to assist with sleep, but had increased his intake to approximately $250 \mathrm{~mL}$ per month, sipping from his bottle every day, often on an hourly basis. He purchased 1,4-BD from the chemical company where he worked and had tried, unsuccessfully, to treat his dependence with alprazolam, which he had last taken earlier in the day. Because the patient had been using alprazolam for only a short period of time prior to presentation, with no history of chronic benzodiazepine use or dependence, benzodiazepine withdrawal was a less likely explanation.

ED diagnostic evaluation was completed and a CT scan of the patient's head was normal. The Poison Control Centre was consulted and recommended hospital admission for 24 hours; however, the patient had been discharged with a prescription for lorazepam before this advice was provided. After 2 days, during which time his medication use and condition were unknown, he presented to a different ED with auditory hallucinations. A repeat CT scan of his head was normal. He was treated with intravenous lorazepam and transferred to the toxicology service at a tertiary care hospital.

Upon arrival at the admitting hospital, the patient's vital signs included a heart rate of 100 beats/min, blood pressure of 140/80 $\mathrm{mm} \mathrm{Hg}$, respiratory rate of 20 breaths/min, oxygen saturation of $96 \%$ on room air and a temperature of $37.4^{\circ} \mathrm{C}$. The patient was mildly delirious with inattention and fluctuating orientation to person, place and time. He reported auditory hallucinations and required physical restraints for agitation. No tremor was noted, and the remainder of his physical examination was normal.

The following laboratory abnormalities were found: aspartate aminotransferase, $294 \mathrm{U} / \mathrm{L}$ (normal value, 10-30 U/L); alanine aminotransferase, $80 \mathrm{U} / \mathrm{L}$ (normal value, $8-20 \mathrm{U} / \mathrm{L}$ ); bilirubin, $63.3 \mathrm{umol} / \mathrm{L}$ (normal value, 3.4-17.1 $\mu \mathrm{mol} / \mathrm{L}$ ); and creatine kinase, $24068 \mathrm{U} / \mathrm{L}$ (normal value, 38-174 U/L). Urine drug screen was positive for benzodiazepines but negative for all other drugs. Gas chromatography-mass spectrometry confirmed the presence of GHB in his urine.

The patient was admitted to the intensive care unit (ICU) with tachycardia, hallucinations and agitation. Sodium bicarbonate was initiated for rhabdomyolysis, and lorazepam and haloperidol were given for combative behaviour and hallucinations. While in hospital, the patient received $44 \mathrm{mg}$ of lorazepam and $27 \mathrm{mg}$ of haloperidol. His symptoms gradually improved, and by the fifth day of hospitalization, his agitation, hallucinations and delirium had resolved. By day 6, his creatine kinase had decreased to $2114 \mathrm{U} / \mathrm{L}$ and the bicarbonate infusion was discontinued. The patient was discharged home on day 6 with no medications after being assessed by psychiatry, who made arrangements for outpatient drug rehabilitation and psychiatric counselling.

\section{Qualitative systematic review}

\section{Search strategy}

We conducted a systematic review of the literature on withdrawal from GHB, 1,4-BD and GBL using electronic 
searches of MEDLINE, EMBASE, Cochrane Database of Systematic Reviews, Cochrane Controlled Trials Register, International Pharmaceutical Abstracts, and the Cumulative Index to Nursing and Allied Health Literature databases (1950-Dec. 31, 2005) that were limited to human studies in English. Search words used were "gamma-hydroxybutyrate," "1,4-butanediol," "gamma-butyrolactone," "withdrawal," "withdrawal syndrome" and "dependence." Reference lists from obtained articles, review papers and 3 toxicology textbooks ${ }^{18-20}$ were hand searched for additional references.

\section{Eligibility criteria}

Inclusion criteria, exclusion criteria and key data elements were identified a priori. Papers were eligible for inclusion if they addressed withdrawal from GHB, 1,4-BD or GBL. We excluded review articles, unpublished manuscripts, reports that focused on intoxication and papers that discussed withdrawal syndromes from unrelated agents. Articles were also excluded if the withdrawal features were not described or if data on more than 2 of the following variables were not included: substance ingested, duration of use, last use prior to presentation or total duration of withdrawal symptoms. Two reviewers (JW and MY) independently reviewed all identified titles and abstracts to determine eligibility. In cases where the title and abstract were not sufficient to determine eligibility for inclusion, the full text of the article was reviewed. Eligibility for final review was based on the consensus of 2 reviewers.

\section{Data elements}

Data collected included patient age, sex, frequency of dosing, dosage used, treatments received, cointoxicants taken, substance ingested (GHB, 1,4-BD or GBL), duration of use, last use prior to presentation, clinical features, total duration of withdrawal symptoms and patient outcome. Once the list of papers to be included was generated, 2 of the authors (JW and MY) independently extracted the data relating to the study variables. Discrepancies were resolved by consensus. Data were entered into a Microsoft Excel database (Microsoft Corporation, Redmond, Washington).

\section{Results}

Our primary search identified 197 potential articles and hand search identified an additional 5. Of these, 167 were excluded when title and abstract review revealed they were not relevant, 5 were excluded because of insufficient reporting of data elements ${ }^{2,21-24}$ and 3 were excluded because of duplicate publication..$^{25-27}$ In cases where the same patient presented with multiple episodes of withdrawal, each episode was considered separately.

Twenty-seven articles, all case series or case reports, fulfilled study eligibility criteria, ${ }^{5-16,28-42}$ describing 57 patients with withdrawal: GHB in 36 cases, 1,4-BD in 3 cases and GBL in 18 cases. Mean age was 31 years (range 18-57 yr) and $65 \%$ (37/57) were male. Figure 1 shows that withdrawal features were similar for all 3 agents and illustrates the frequency of symptoms for each substance. The most common withdrawal symptoms were tremor (67\%), hallucinations (63\%), tachycardia (63\%), insomnia (58\%), anxiety $(46 \%)$ and hypertension (44\%). Other symptoms included agitation $(40 \%)$, diaphoresis $(35 \%)$, paranoia $(25 \%)$, confusion $(21 \%)$, delusions $(18 \%)$, delirium $(12 \%)$, nystagmus $(8 \%)$, rhabdomyolysis $(7 \%)$ and seizures $(7 \%)$. One death occurred in a patient withdrawing from GHB. ${ }^{5}$

The median duration of use prior to withdrawal presentation was 16 months for GHB, 1.25 months for 1,4-BD and 4 months for GBL. The median interval between last use and withdrawal presentation was 7.5 hours for GHB, 6 hours for 1,4-BD and 72 hours for GBL. The mean duration of withdrawal symptoms was 8 days ( $10 \mathrm{~d}$ for GHB, 4 days for 1,4-BD and 6.5 days for GBL). For the 33 cases where frequency of dosing was available, the mean interval between doses was 5 hours, with a range of 30 minutes to 24 hours, usually as a bedtime dose. It was difficult to report on the dosage used as this was reported in a number of non-equivalent measures (e.g., teaspoons, capfuls, bottles, sips, droppers, grams/day and tablets). Concentration of the substance used was infrequently reported; therefore, data on dosage was not included.

Table 1 shows that $51(89.5 \%)$ of 57 patients received

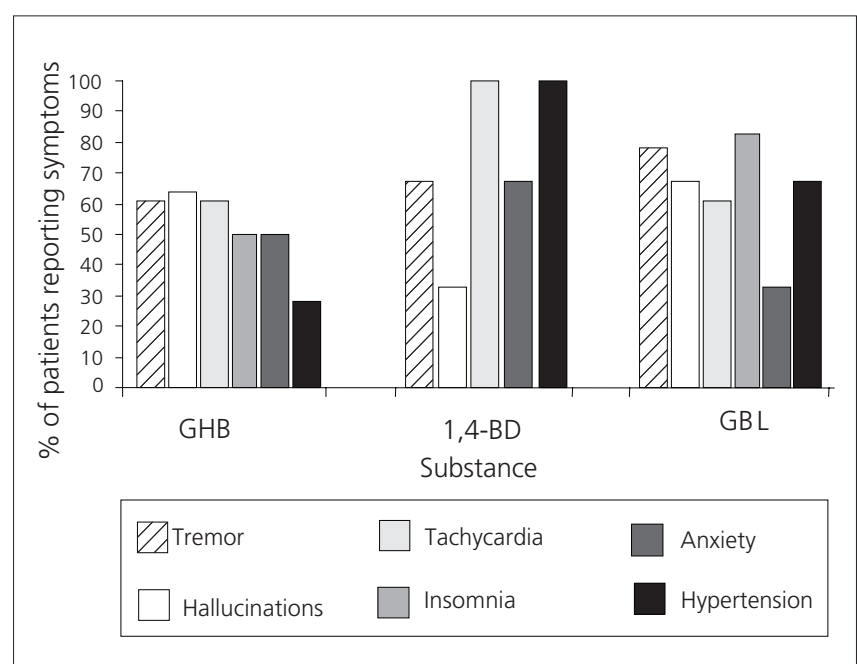

Fig. 1. Commonly reported symptoms of withdrawal from gamma-hydroxybutyrate (GHB), 1,4-butanediol (1,4-BD) and gamma-butyrolactone (GBL). 
benzodiazepine treatment for withdrawal. Forty patients were treated with benzodiazepines in addition to other medications, while $11(19.3 \%)$ received benzodiazepines alone. One patient received only barbiturates, and 3 had no treatment (including 2 whose symptoms had resolved and 1 who declined treatment). Treatment information was not available for 1 patient. Table 2 summarizes data describing coingestions around the time of withdrawal. This information is based on toxicology results and patient history.

\section{Discussion}

\section{Use and availability}

Despite the fact that federal legislation in Canada has made GHB and its analogues illegal to possess, they continue to

\begin{tabular}{|c|c|}
\hline Medication or class & No. (and \%) of patients \\
\hline Antipsychotics* & $25(62.5)$ \\
\hline Antiepilepticst & $9(22.5)$ \\
\hline Barbiturates $\ddagger$ & $7(17.5)$ \\
\hline Clonidine & $5(12.5)$ \\
\hline Antiemetics§ & $4(10.0)$ \\
\hline Baclofen & $4(10.0)$ \\
\hline Chloral hydrate & $3(7.5)$ \\
\hline Propofol & $3(7.5)$ \\
\hline$\beta$-Blockersף & $3(7.5)$ \\
\hline Trazadone & $2(5.0)$ \\
\hline Paroxetine & $2(5.0)$ \\
\hline Bromocriptine & $1(2.5)$ \\
\hline Fentanyl & $1(2.5)$ \\
\hline Physostigmine & $1(2.5)$ \\
\hline
\end{tabular}

*Haloperidol, risperidone, olanzapine, quetiapine, fluphenazine, trifluoperazine or chlorpromazine.

†Valproic acid, phenytoin, carbamazepine or gabapentin.

¥Phenobarbital or pentobarbital.

$\S$ Diphenhydramine or droperidol.

IPropranolol, atenolol or labetolo.

Table 2. Coingestions near the time of withdrawal, $n=57$

\begin{tabular}{lc} 
Substance* & No. (and \%) of patients \\
\hline None & $34(59.6)$ \\
Marijuana & $8(14)$ \\
Cocaine & $7(12.3)$ \\
Benzodiazepines & $6(10.5)$ \\
Alcohol & $6(10.5)$ \\
Opiates & $4(7.0)$ \\
Amphetamines & $3(5.3)$ \\
Ecstasy & $2(3.5)$ \\
Anabolic steroids & $2(3.5)$ \\
Barbiturates & $1(1.8)$ \\
Lysergic acid diathylamide & $1(1.8)$ \\
\hline *Patients often used more than 1 of these substances. & \\
\hline
\end{tabular}

be popular as drugs of abuse. ${ }^{4}$ The problem is exacerbated by the fact that 1,4-BD and GBL are still available in industrial solvents or as a "natural" component of dietary supplements, making them relatively accessible. ${ }^{2}$ Furthermore, GHB and its analogues are not detected on standard drug screens, increasing their attractiveness as drugs of abuse. ${ }^{2,6}$ GHB is rapidly cleared from the urine, making detection difficult. One study found that GHB doses of $75-100 \mathrm{mg} / \mathrm{kg}$ would be undetectable in the urine by 12 hours after administration. ${ }^{43}$ Although abuse of GHB and its analogues continues to be a problem, documented cases of withdrawal from these agents remain relatively uncommon.

\section{Metabolism and withdrawal features}

The metabolism of 1,4-BD to GHB is illustrated in Figure 2. Chronic use of GHB can lead to down-regulation of endogenous gamma-aminobutyric acid (GABA) receptors, whereas withdrawal of GHB and its analogues results in decreased GABA mediated inhibition of excitatory neurotransmitters. ${ }^{5,13,28}$ The neuromodulatory effects of GHB and its analogues are complex and are described in detail in reviews by Wong and colleagues, ${ }^{44}$ and Snead and coauthors. ${ }^{45}$ Endogenous GHB is believed to mediate activity primarily through GHB specific receptors, while exogenously administered GHB primarily acts via GABA-B receptors. GHB is believed to possess partial agonist activity at the GABA-B receptor, and further activity may be related to conversion of GHB to GABA. Neuroinhibition occurs through pre- and post-synaptic GABA-B receptor activation. Inhibition of pre-synaptic voltage-gated calcium channels leads to reduced neurotransmitter release, and the increased opening of inward rectifying potassium channels results in reduced post-synaptic excitability. GHB also has

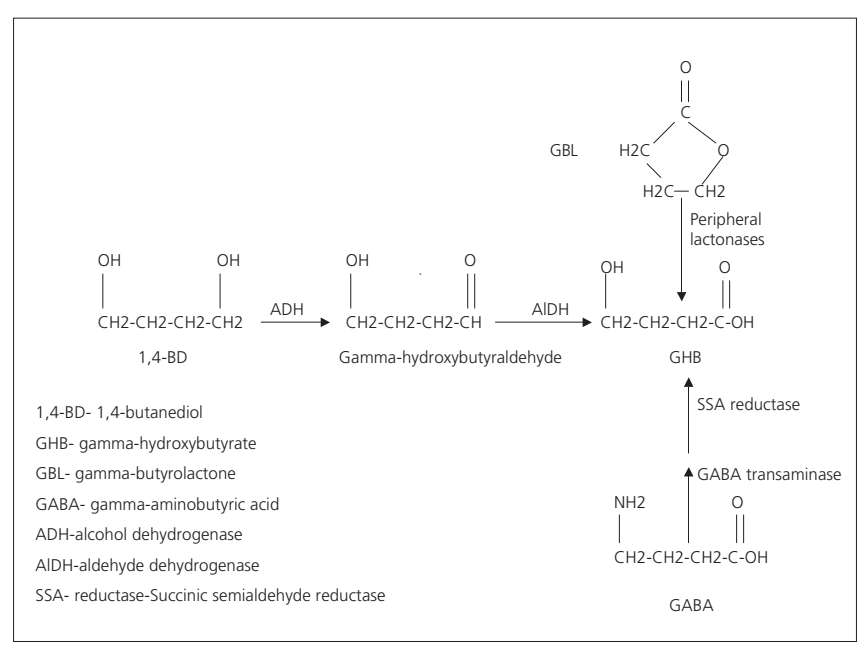

Fig. 2. The metabolism of 1,4-butanediol (1,4-BD) and gammabutyrolactone (GBL) to gamma-hydroxybutyrate (GHB). 
effects on dopamine, acetylcholine, serotonin, glutamate and opiate neurotransmission. ${ }^{44,45}$

GHB-related withdrawal is characterized by CNS and autonomic dysfunction similar to other sedative withdrawal syndromes ${ }^{17}$; however, there are some important differences. First, withdrawal severity may be different depending on the substance used. Ethanol withdrawal often causes severe autonomic dysfunction with moderate to severe CNS symptoms; benzodiazepine withdrawal causes moderate autonomic instability and CNS symptoms; and GHB withdrawal tends to cause mild autonomic dysfunction with severe CNS symptoms. ${ }^{5,17}$ Our review suggests that autonomic and CNS abnormalities are both prevalent in withdrawal from GHB and its analogues. Second, the mortality rates for ethanol and benzodiazepine withdrawal have been reported as $5 \%-15 \%$ and $1 \%$, respectively. ${ }^{5}$ In contrast, only 1 death has been reported in the setting of GHB withdrawal.

\section{Treatment}

Benzodiazepines are selective GABA-A receptor agonists ${ }^{13,46}$ that cause GABA-activated chloride channels to open. Chloride influx hyperpolarizes neurons, thereby increasing CNS inhibitory tone and mitigating the unopposed CNS stimulation that may occur with GHB related withdrawal states. ${ }^{13,46}$ Benzodiazepines are therefore useful agents for treatment of these patients, although high doses may be required. ${ }^{6.29} \mathrm{In}$ cases where benzodiazepines are ineffective in controlling symptoms, treatment with pentobarbital may be appropriate. Sivilotti and colleagues ${ }^{15}$ identified 4 patients withdrawing from GBL who had an inadequate response to benzodiazepines but experienced rapid symptom control following pentobarbital administration. In an algorithm designed for in- and outpatient treatment of withdrawal from GHB and its precursors, McDonough and colleagues ${ }^{47}$ recommend the initial use of benzodiazepines, followed by pentobarbital in refractory cases.

\section{Limitations}

The details of our case are limited because we had no contact with the patient between the first and second ED visit. As a result, some details about his clinical course and medication use were unavailable. The available information does, however, serve to illustrate the spectrum and duration of symptoms that may be anticipated for withdrawal from GHB or its analogues. There are several limitations to the literature review. All studies included in the review were either case series or case reports. Several withdrawal symptoms were subjective and difficult to define. In addition, all patients were not examined at consistent intervals, which may compromise the validity of time-related analyses (e.g., withdrawal duration). Some events and symptoms attributed to GHB withdrawal could have been due to unrecognized conditions or cointoxicants. Finally, it is difficult to determine what relation, if any, exists between withdrawal features and the amount of drug ingested, because the majority of reported cases were diagnosed based on historical features without laboratory confirmation or quantitative determination of GHB levels.

\section{Conclusion}

Withdrawal from GHB and its analogues results in features similar to other sedative-hypnotic withdrawal syndromes. Diagnosis is based on historical and clinical features. Symptoms may be severe, often requiring hospitalization. Although uncommon, seizures and death may occur. No prospective, randomized trials have clarified the best therapeutic approach; however, benzodiazepines are frequently used for initial treatment and barbiturates for more severe or refractory cases. Withdrawal from GHB, 1,4-BD and GBL should be considered in the differential diagnosis of patients presenting with features of a sedative-hypnotic withdrawal syndrome.

Competing interests: None declared.

\section{References}

1. Dyer J. Gamma-hydroxybutyrate: a health food product producing coma and seizure like activity. Am J Emerg Med 1991;9: 321-4.

2. Zvosec DL, Smith SW, McCutcheon JD, et al. Adverse events, including death, associated with the use of 1,4-Butanediol. N Engl J Med 2001;344:87-94.

3. Takahara J, Yunoki S, Yakushiji W, et al. Stimulatory effects of gamma-hydroxybutyric acid on growth hormone and prolactin release in humans. J Clin Endocrinol Metab 1977;44:1014-7.

4. Controlled Drugs and Substances Act. 1996, c. 19 Available: http://laws.justice.gc.ca/en/ShowFullDoc/cs/C-38.8///en (accessed 2007 Nov 21).

5. Dyer JE, Roth B, Hyma BA. Gamma-hydroxybutyrate withdrawal syndrome. Ann Emerg Med 2001;37:147-53.

6. Craig K, Gomez HF, McManus JL, et al. Severe gamma-hydroxybutyrate withdrawal: a case report and literature review. J Emerg Med 2000;18:65-70.

7. Catalano MC, Glass JM, Catalano G, et al. Gamma butyrolactone (GBL) withdrawal syndromes. Psychosomatics 2001;42: 83-8.

8. Greene T, Dougherty T, Rodi A. Gamma-butyrolactone (GBL) withdrawal presenting as acute psychosis. J Toxicol Clin Toxicol 1999;37:651.

9. Herold AH, Sneed KB. Treatment of a young adult taking 
gamma-butyrolactone (GBL) in a primary care clinic. J Am Board Fam Pract 2002;15:161-3.

10. McDaniel CH, Miotto KA. Gamma hydroxybutyrate (GHB) and gamma butyrolactone (GBL) withdrawal: five case studies. J Psychoactive Drugs 2001;33:143-9.

11. Mycyk MB, Wilemon C, Aks SE. Two cases of withdrawal from1,4-butanediol use. Ann Emerg Med 2001;38:345-6.

12. Reeves J, Duda R. GHB/GBL intoxication and withdrawal: a review and case presentation. Addictive Disorders \& Their Treatment 2003;2:25-8.

13. Schneir AB, Ly BT, Clark RF. A case of withdrawal from the GHB precursors gamma-butyrolactone and 1,4-Butanediol. J Emerg Med 2001;21:31-3.

14. Sharma AN, Nelson L, Hoffman RS. Severe gamma butyrolactone withdrawal. J Toxicol Clin Toxicol 2000;38:535.

15. Sivilotti MLA, Burns MJ, Aaron CK, et al. Pentobarbital for severe gamma-butyrolactone withdrawal. Ann Emerg Med 2001;38:660-5.

16. Wojtowicz JM, Yarema MC, Wax PM. A case of prolonged withdrawal from use of 1,4-butanediol complicated by seizure and rhabdomyolysis [abstract]. CJEM 2006;8:195.

17. Tarabar AF, Nelson LS. The gamma-hydroxybutyrate withdrawal syndrome. Toxicol Rev 2004;23:45-9.

18. Goldfrank LR, Flomenbaum NE, Lewin NA, et al. Goldfrank's toxicologic emergencies. 7th ed. New York (NY): McGrawHill; 2002.

19. Ford MD, Ling LJ, Delaney KA, et al. Clinical toxicology. 1st ed. Philadelphia (PA): W.B. Saunders; 2001.

20. Haddad LM, Shannon MW, Winchester JF. Clinical management of poisoning and drug overdose. 3rd edition. Philadelphia (PA): W.B. Saunders; 1997.

21. Gonzalez A, Nutt DJ. Gamma hydroxyl butyrate abuse and dependency. J Psychopharmacol 2005;19:195-204.

22. Miotto K, Darakjian J, Basch J, et al. Gamma-hydroxybutyric acid: patterns of use, effects and withdrawal. Am J Addict 2001;10:232-41.

23. Mullins ME, Fitzmaurice SC. Lack of efficacy of benzodiazepines in treating gamma-hydroxybutyrate withdrawal. J Emerg Med 2001;20:418-9.

24. Garvey R, Fitzmaurice B. Withdrawal delirium with dance drug 'liquid ecstasy' (GHB). Ir J Psych Med 2004;21:73-5.

25. Dyer JE, Andrews KM. Gamma hydroxybutyrate withdrawal. J Toxicol Clin Toxicol 1997;35:553-4.

26. Dyer JE, Roth B, Hyma BA. GHB withdrawal syndrome: 8 cases. J Toxicol Clin Toxicol 1999;37:650.

27. Galloway GP, Frederick SL, Staggers F Jr. Physical dependence on sodium oxybate. Lancet 1994;343:57.

28. Chew G, Fernando A. III. Epileptic seizure in GHB withdrawal. Australas Psychiatry 2004;12:410-1.

29. Chin RL. A case of severe withdrawal from gamma-hydroxybutyrate. Ann Emerg Med 2001;37:551-2.

30. Addolorato G, Caputo F, Capristo E, et al. A case of gammahydroxybutyric acid withdrawal syndrome during alcohol addic- tion treatment: utility of diazepam administration. Clin Neuropharmacol 1999;22:60-2

31. Bowles TM, Sommi RW, Amiri M. Successful management of prolonged gamma-hydroxybutyrate and alcohol withdrawal. Pharmacotherapy 2001;21:254-7.

32. Friedman J, Westlake R, Furman M. "Grievous bodily harm:" gamma hydroxybutyrate abuse leading to a Wernicke-Korsakoff syndrome. Neurology 1996;46:469-71.

33. Galloway GP, Frederick SL, Staggers FE Jr, et al. Gamma-hydroxybutyrate: an emerging drug of abuse that causes physical dependence. Addiction 1997;92:89-96.

34. Glasper A, McDonough M, Bearn J. Within-patient variability in clinical presentation of gamma-hydroxybutyrate withdrawal a case report. Eur Addict Res 2005;11:152-4.

35. Hernandez M, McDaniel CH, Costanza CD, et al. GHB-induced delirium: a case report and review of the literature on gamma hydroxybutyric acid. Am J Drug Alcohol Abuse 1998;24:179-83.

36. Hutto B, Fairchild A, Bright R. gamma-Hydroxybutyrate withdrawal and chloral hydrate. Am J Psychiatry 2000;157:1706.

37. Mahr G, Bishop CL, Orringer DJ. Prolonged withdrawal from extreme gamma-hydroxybutyrate (GHB) abuse. Psychosomatics 2001;42:439-40

38. Miglani JS, Kim KY, Chahil R. Gamma-hydroxybutyrate withdrawal delirium: a case report. Gen Hosp Psychiatry 2000; 22:213-6

39. Price G. In-patient detoxification after GHB dependence. $\mathrm{Br} \mathrm{J}$ Psychiatry 2000;177:181.

40. Rosenberg MH, Deerfield LJ, Baruch EM. Two cases of severe gamma-hydroxybutyrate withdrawal delirium on a psychiatric unit: recommendations for management. Am J Drug Alcohol Abuse 2003;29:487-96

41. Slagel B, Kingstone E, Bhalerao S. Gamma hydroxybutyrate withdrawal in an orthopedic trauma patient. Can J Psychiatry 2003;48:131-2.

42. Trendelenburg G, Heinz A, Strohle A. Gamma-hydroxybutyrate dependence with social phobia. Am J Psychiatry 2004;161:375-6.

43. Hoes MJ, Vree TB, Guelen PJ. Gamma-hydroxybutyric acid as hypnotic: clinical and pharmacokinetic evaluation of gamma-hydroxybutyric acid as hypnotic in man. Encephale 1980;6:93-9.

44. Wong CGT, Chan KFY, Gibson KM, et al. Gamma-hydroxybutyric acid: neurobiology and toxicology of a recreational drug. Toxicol Rev 2004;23:3-20.

45. Snead OC III, Gibson KM. Gamma-hydroxybutyric acid. N Engl J Med 2005;352:2721-32.

46. Rang HP, Dale MM, Ritter JM. Anxiolytic and hypnotic drugs. In: Pharmacology. 4th ed. Edinburgh (UK): Churchill Livingstone; 1999. p 531-2.

47. McDonough M, Kennedy N, Glasper A, et al. Clinical features and management of gamma-hydroxybutyrate (GHB) withdrawal: a review. Drug Alcohol Depend 2004;75:3-9.

Correspondence to: Dr. Jeremy Wojtowicz, Department of Emergency Medicine, Room C231 Foothills Medical Centre, 1403-29 St. NW, Calgary AB T2N 2T9; jmwojtow@ucalgary.ca 